\title{
Mycotoxin exposure is associated with increased risk of esophageal squamous cell carcinoma in Huaian area, China
}

\author{
Kathy S. Xue ${ }^{1}$, Lili Tang ${ }^{1}$, Guiju Sun², Shaokang Wang ${ }^{2}, \mathrm{Xu} \mathrm{Hu}^{3}$ and Jia-Sheng Wang ${ }^{1 *}$ (D)
}

\begin{abstract}
Background: Consumption of moldy food has previously been identified as a risk factor for esophageal squamous cell carcinoma (ESCC) in high-risk countries; however, what contributing roles these dietary carcinogenic mycotoxins play in the etiology of ESCC are largely unknown.

Methods: A mycotoxin biomarker-incorporated, population-based case-control study was performed in Huaian area, Jiangsu Province, one of the two high-risk areas in China. Exposure biomarkers of aflatoxins (AF) and fumonisins (FN) were quantitatively analyzed using HPLC-fluorescence techniques.

Results: Among the cases $(n=190)$, the median levels of AF biomarker, serum AFB ${ }_{1}$-lysine adduct, and FN biomarker, urinary $\mathrm{FB}_{1}$, were $1.77 \mathrm{pg} / \mathrm{mg}$ albumin and $176.13 \mathrm{pg} / \mathrm{mg}$ creatinine, respectively. Among the controls ( $n=380$ ), the median levels of $\mathrm{AFB}_{1}$-lysine adduct and urinary $\mathrm{FB}_{1}$ were $1.49 \mathrm{pg} / \mathrm{mg}$ albumin and $56.92 \mathrm{pg} / \mathrm{mg}$ creatinine, respectively. These mycotoxin exposure biomarker levels were significantly higher in cases as compared to controls ( $p<0.05$ and 0.01 , respectively). An increased risk to ESCC was associated with exposure to both $\mathrm{AFB}_{1}$ and $\mathrm{FB}_{1}$ ( $p<0.001$ for both).

Conclusions: Mycotoxin exposure, especially to $\mathrm{AFB}_{1}$ and $\mathrm{FB}_{1}$, was associated with the risk of ESCC, and a greaterthan-additive interaction between co-exposures to these two mycotoxins may contribute to the increased risk of ESCC in Huaian area, China.
\end{abstract}

Keywords: Aflatoxin $B_{1}$, Co-exposure, Fumonisin $B_{1}$, Esophageal cancer, Molecular epidemiology, Mycotoxins

\section{Background}

Esophageal cancer is one of the most common cancers worldwide, ranked 7th in incidence in males, 6th and 9th in cancer-related death in males and females worldwide, respectively [1], and considerably higher in both incidence and cancer-related death in many developing countries [1-3]. The highest incidences of esophageal cancer were found in East and Southern Africa, Northern France, and Central Asia, with the notorious "Central Asia esophageal cancer belt" extending from northeastern China westward to northern Iran along the Silk Road, spanning several countries including China, Turkmenistan, Uzbekistan, Karakalpakstan, Kazakhstan,

\footnotetext{
* Correspondence: jswang@uga.edu

${ }^{1}$ Department of Environmental Health Science, College of Public Health,

University of Georgia, 150 Green Street, Athens, GA 30602, USA

Full list of author information is available at the end of the article
}

and Iran [2-4]. There are two main types of esophageal cancers, namely, the squamous cell carcinoma (ESCC), and adenocarcinoma (EAC). ESCC constitutes of majority of esophageal cancer cases, and was more prevalent with high incidences in developing nations such as China, with the primary risk factor being dietary patterns and environmental factors, as well as individual genetic predispositions [1,5]. Whereas for EAC, the rates are increasing in the US and other developed nations in past decades, and the risks were postulated to be linked to obesity, as well as various preexisting conditions, such as Barrett's esophagus and reflux symptoms [6].

Consumption of moldy and mycotoxin-contaminated food has previously been identified as a risk factor for ESCC in high-risk countries $[5,7,8]$; however, what contributing roles thesedietary carcinogenic mycotoxins play

(c) The Author(s). 2019 Open Access This article is distributed under the terms of the Creative Commons Attribution 4.0 International License (http://creativecommons.org/licenses/by/4.0/), which permits unrestricted use, distribution, and reproduction in any medium, provided you give appropriate credit to the original author(s) and the source, provide a link to the Creative Commons license, and indicate if changes were made. The Creative Commons Public Domain Dedication waiver (http://creativecommons.org/publicdomain/zero/1.0/) applies to the data made available in this article, unless otherwise stated. 
in the etiology of ESCC are largely unknown. Aflatoxin $\mathrm{B}_{1}\left(\mathrm{AFB}_{1}\right)$ and fumonisin $\mathrm{B}_{1}\left(\mathrm{FB}_{1}\right)$ are among the most well-known mycotoxins found in commonly consumed foods and feed products [9]. $\mathrm{AFB}_{1}$, a Group 1 human carcinogen and a representative of the aflatoxin family, is produced by fungal contaminants, Aspergillus flavus and $A$. parasiticus [10]. It is considered to be a major food contaminant worldwide, affecting food and products of, including but not limited to, corn, peanuts, milo, sorghum, copra, and rice [11]. $\mathrm{FB}_{1}$, on the other hand, is a Group 2B carcinogen and a representative of fumonisin family, produced primarily by maize pathogens, Fusarium verticillioides and $F$. proliferatum, which contaminates maize and maize-based products ubiquitously $[12,13]$. As both Aspergillus and Fusarium can contaminate and often co-exist on maize and some other cereal grains, concerns for human co-exposure to these two mycotoxins, and its consequences, have been raised [14, 15]. Co-existence of $\mathrm{AFB}_{1}$ and $\mathrm{FB}_{1}$ in food items has already been reported in several studies worldwide, particularly from Asia, South and Central America, and Africa [16-21]. Consequently, efforts must now be made to assess the extent of human co-exposure to these mycotoxins, as well as the adverse health effects they may have, in order to more accurately assess the risk posed by the nature of co-contamination and co-exposure [22].

Dietary $\mathrm{FB}_{1}$ exposure has been proposed as one of the major environmental factors associated with increased risk of ESCC in developing countries [23]. The first association between $\mathrm{FB}_{1}$ and human esophageal cancer was proposed by Sydenham el al., who reported $\mathrm{FB}_{1}$ contamination in the Transkei region, a high incidence area of esophageal cancer in Africa [7, 23]. In Huaian, China, another high-risk area for ESCC, $\mathrm{FB}_{1}$ was detected in $95.7 \%(112 / 117)$ of corn samples, with an average of $2.84 \mathrm{mg} / \mathrm{kg}$ (range: $0.1-25.5 \mathrm{mg} / \mathrm{kg}$ ) [24]. Cocontamination of $\mathrm{FB}_{1}$ with other mycotoxins, particularly $\mathrm{AFB}_{1}$, has also been reported in this high ESCC risk area. In Huaian area, the mean level of $\mathrm{AFB}_{1}$ in food was estimated to be $13.5 \mu \mathrm{g} / \mathrm{kg}$, with estimated daily intake of $1.723 \mu \mathrm{g}$ (range $0.224-49.772 \mu \mathrm{g}$ ) [19]. Similarly, in high risk areas of Cixian and Linxian counties, China, co-contamination of $\mathrm{AFB}_{1}$ and $\mathrm{FB}_{1}$ were detected at mean levels of $8.61 \mu \mathrm{g} / \mathrm{kg}$ (range: $1-38.4 \mu \mathrm{g} / \mathrm{kg}$ ) and 35.3 $\mathrm{mg} / \mathrm{kg}$ (range: $20-60 \mathrm{mg} / \mathrm{kg}$ ), respectively [8].

The use of molecular biomarkers, facilitated by understanding of toxicokinetics and toxicodynamics of environmental toxicants, has improved the assessment of individual exposure beyond the levels detected in external media, such as in food, as well as estimations based on questionnaires [25]. For $\mathrm{AFB}_{1}$, the most widely acceptable exposure biomarker is serum $\mathrm{AFB}_{1}$-lysine adducts, formed by covalently binding of $\mathrm{AFB}_{1}$-diol with lysine residue on serum albumin [11]. It is reasonably stable in blood until albumin turnover, thus making the levels of this adduct highly reflective of chronic exposure [11]. This adduct has been validated and utilized as a reliable indicator of chronic exposure in both animal and human epidemiological studies $[11,26]$. For $\mathrm{FB}_{1}$, the orally dosed toxin is poorly absorbed and rapidly eliminated with no major metabolites produced in humans; nonetheless, the parent compound can be measured directly in biological fluids, such as urine, as a biomarker of $\mathrm{FB}_{1}$ exposure, which has also been validated in human population studies [27-31].

Dietary exposure to mycotoxins has been linked to the etiology of several gastrointestinal cancer sites and chronic diseases in many developing countries [7, 9, 32, 33]. The co-contamination of AFs and FNs in human diets has been widely reported, and epidemiological studies have indicated the potential contributory effect of the two mycotoxins in etiologies of human liver and esophageal cancer [19, 20, 34, 35]. Combinative exposure to the two mycotoxins often showed greater toxic effects, and potentially synergistic effects on tumorigenesis, in animal and human cell models, when compared to either $\mathrm{AFB}_{1}$ or $\mathrm{FB}_{1}$ alone [36-38]. To better understand the contributing roles and mechanisms these exposures have in human esophageal carcinogenesis, we used biomarker approach to evaluate their contributing risk of ESCC, specifically, serum $\mathrm{AFB}_{1}$-lysine and urinary $\mathrm{FB}_{1}$. Furthermore, we examined potential interactions, including additive effects, between mycotoxin exposures and increased risk of ESCC in Huaian, China.

\section{Methods}

\section{Chemicals and reagents}

$\mathrm{AFB}_{1}$-lysine adduct standard was synthesized and purified as previously described by Sabbioni et al. [39] Albumin determination reagent (bromocreosol purple), and normal human serum were purchased from Sigma Aldrich Chemical Co. (St. Louis, MO). Pronase (25 kU, Nuclease-free) was purchased from Calbiochem (La Jolla, CA). Protein assay dye reagent concentrate and protein standards were purchased from Bio-Rad Laboratories Inc. (Hercules, CA). Boric acid, o-phthaldialdehyde (OPA), 2mercaptoethanol, $\mathrm{FB}_{1}$ from $F$. verticilioides ( 98\% purity, TLC), 10× phosphate buffered saline (PBS), ammonium hydroxide, ammonium acetate, sodium chloride, sodium phosphate monobasic, hydrochloric acid, and formic acid were purchased from Sigma-Aldrich (St. Louis, MO, USA). OPA reagents were prepared by dissolving $10 \mathrm{mg}$ of OPA and $30 \mu \mathrm{l}$ of 2 -mercaptoethanol in $250 \mu \mathrm{l}$ of methanol and mixing with $4.75 \mathrm{ml}$ of $3 \%$ boric acid buffer $(\mathrm{pH}$ 10.5) and stored at $4{ }^{\circ} \mathrm{C}$ avoiding light before use. Mixed mode solid phase extraction (SPE) cartridges, as well as Sep-Pak reversed phase $\mathrm{C} 18$ cartridges were purchased 
from the Waters Corp. (Milford, MA). All other chemicals and solvents were of highest grade and purity available.

\section{Study site and populations}

Huaian area, located in the northern area of Jiangsu Province of China, is one of the two endemic areas for esophageal cancers in China (the other being the southern Taihang Mountain area, including Linzhou of Henan Province and Cixian of Hebei Province), with incidence over 80 per 100,000, six times greater than the national average rate [5]. The study followed a population-based case-control design, with the participants recruited from five rural farming communities (townships) belonging to the Huaian District. The location of the study site is shown in Fig. 1. Cases consist of ESCC diagnosed in 2006-2007 from the malignant tumor registration record, and healthy controls were matched by age, gender, and residency. After signed written consent, a face-to- face interview was conducted, and a total of 190 cases and 380 controls were recruited. Questionnaire on demographics $[5,40]$, disease history and dietary pattern, blood sample $(5 \mathrm{~mL})$, and the morning urine sample (50 $\mathrm{mL}$ ) were collected. Personnel conducting laboratory analyses were blinded to case and control status. The study protocols including ethics guideline and consent form were approved by the Institutional Review Boards for human subjects at Southeast University School of Public Health and Texas Tech University (human subject assurance number: 00001568) and was compliant with human research guidelines of the respective institutions.

\section{HPLC-FLD analysis of serum $\mathrm{AFB}_{1}$-lysine adduct}

Overall sample processing used a method previously reported in Qian et al. 2013 [41]. Briefly, thawed human serum samples underwent pathogen deactivation via

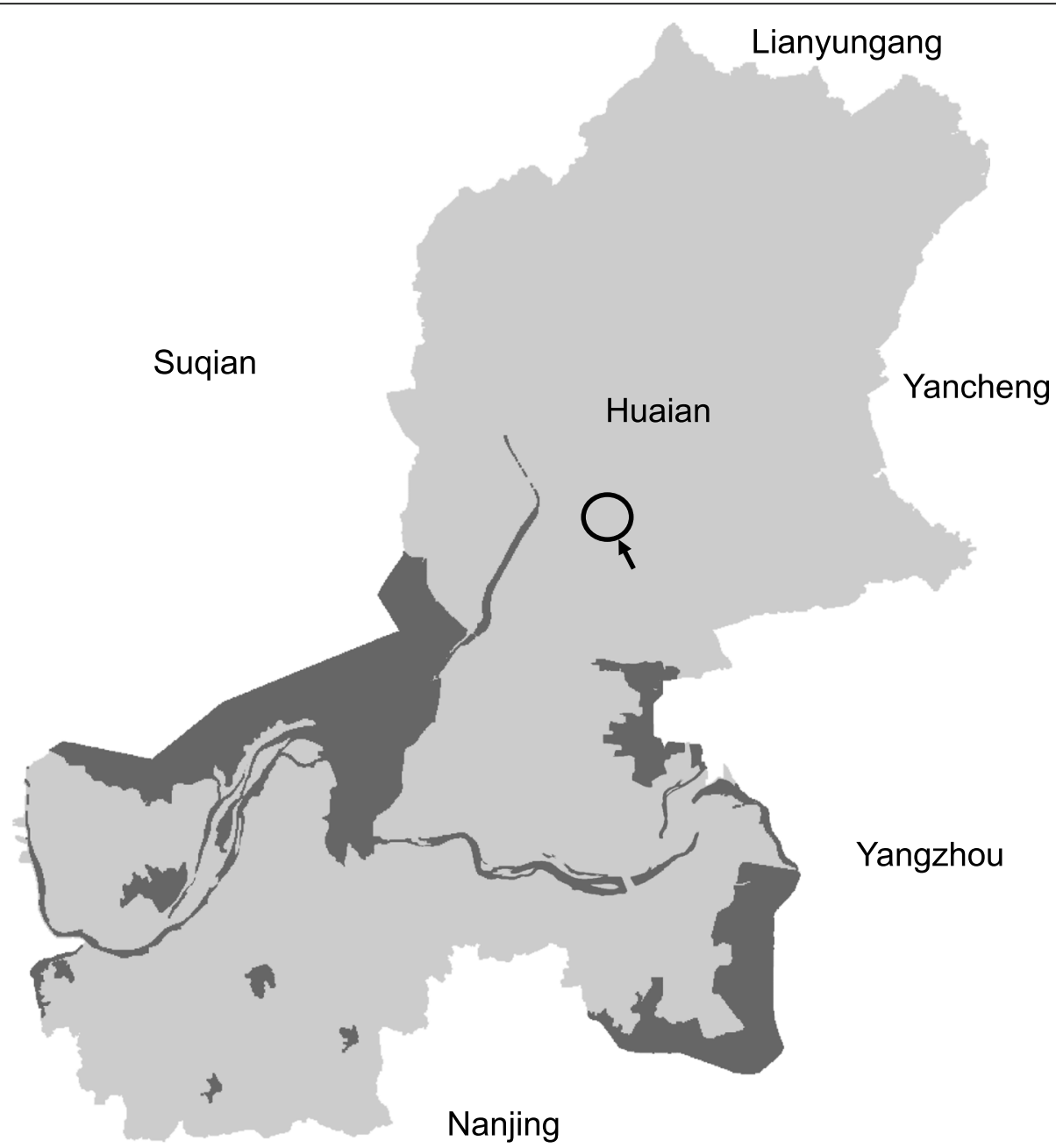

Fig. 1 Map of Huaian area, Jiangsu Province, China. Circled with arrow indicate the townships where the study participants were recruited for this case-control study. Map of Huaian was traced using Adobe Photoshop CS2 (https://www.adobe.com/), with texts and indicators added with Microsoft PowerPoint (https://www.microsoft.com/en-us/). No copyright issue present 
submerging sample tubes in $56^{\circ} \mathrm{C}$ water bath for $30 \mathrm{~min}$. Serum albumin and total protein were analyzed with respective reagents, as described previously. An aliquot of $150 \mu \mathrm{l}$ serum was then digested via pronase (1:4 pronase: total protein, w:w), in $37^{\circ} \mathrm{C}$ water bath for $3 \mathrm{~h}$ to optimize the conditions of enzyme digestion in order to release lysine adducts. The contents were then purified via solid phase extraction, using Waters MAX SPE cartridges over vacuum chamber manifold. Samples were eluted with $2 \%$ formic acid in methanol, vacuum-dried with a Labconco Centrivap concentrator, and reconstituted with $150 \mu \mathrm{l}$ of $25 \%$ methanol prior to injection.

$\mathrm{AFB}_{1}$-lysine adduct was quantified using Agilent 1100 HPLC-fluorescence detection system (Agilent Technologies, Wilmington, DE, USA), at excitation/ emission of $405 / 470 \mathrm{~nm}$. Chromatographic separations were achieved using Zorbax Eclipse XDB-C18 reverse phase column $(5 \mu \mathrm{m}, 4.6 \times 250 \mathrm{~mm})$, with a gradient of $20 \mathrm{mM} \mathrm{NH} \mathrm{H}_{2} \mathrm{PO}_{4}$, pH 7.2 (Buffer A), and $100 \%$ methanol (Buffer B), to achieve separation within 25 $\mathrm{min}$ at flow rate of $1.0 \mathrm{ml} / \mathrm{min}$. For each injection, $100 \mu \mathrm{l}$ of processed samples were used. Final concentrations were obtained via manual integration and calculation using a standard curve, then adjusted by albumin content of corresponding samples, to obtain the exposure parameters in units of $\mathrm{pg} / \mathrm{mg}$ albumin. The limit of detection for the method used is $0.4 \mathrm{pg}$ $\mathrm{AFB}_{1}$-lysine /mg albumin.

\section{Measurement of urinary Creatinine}

Creatinine concentration in urine samples was analyzed using the 96-well Creatinine Assay Kit from Cayman Chemical (Ann Arbor, MI, USA). The analysis is based on a modified Jaffe colorimetric method that measures the difference in absorbance $(495 \mathrm{~nm})$ of the creatininepicrate complex before and after acidification. The assay was carried out according to manufacturer's instructions, and absorbance was measured using an ELx808 Absorbance Microplate Reader from BioTek Instruments, Inc. (Winooski, VT, USA).

\section{HPLC-FLD analysis of urinary $\mathrm{FB}_{1}$}

Urinary $\mathrm{FB}_{1}$ was analyzed based on previous studies [42]. Briefly, $10 \mathrm{ml}$ aliquot of urine samples were centrifuged to remove pellets. The supernatant was passed through FumoniTest column by gravity. After washing with $10 \mathrm{~mL} 1 \mathrm{x}$ PBS, $\mathrm{FB}_{1}$ was eluted three times with $0.5 \mathrm{~mL}$ of $20 \%$ methanol in $10 \mathrm{mM}$ hydrochloric acid directly onto pre-conditioned Waters Oasis HLB cartridge and sequentially washed with HPLC grade water and $25 \%$ methanol, three times each. The contents were then eluted with $2 \%$ formic acid in methanol and dried under a gentle stream of nitrogen gas while incubated in $35^{\circ} \mathrm{C}$ water bath.
Dried residues were then reconstituted with $200 \mu \mathrm{l}$ $50 \%$ methanol, and $150 \mu \mathrm{l}$ were transferred to injection vial for analysis.

HPLC analysis was performed with Agilent 1100 HPLC-fluorescence detection system. On-line derivatization of analytes with OPA reagent was performed via injection program, which mixes $10 \mu \mathrm{l}$ of reagent with sample for $1 \mathrm{~min}$ prior to injection. The injection volume was 100 ul. Chromatographic separation achieved Zorbax Eclipse XDB-C18 reverse phase column $(5 \mu \mathrm{m}, 4.6 \times 250 \mathrm{~mm})$ maintained at $35^{\circ} \mathrm{C}$. The mobile phases consist of $0.1 \mathrm{M}$ sodium phosphate monobasic (pH 3.4) (Buffer A) and methanol (Buffer B). The flow rate of mobile phase was $1.0 \mathrm{~mL} / \mathrm{min}$, consisting of linear gradient starting from Buffer A: Buffer B $(35: 65, \mathrm{v} / \mathrm{v})$ to Buffer A: Buffer B $(20: 80$, v/v) over $13 \mathrm{~min}$. OPA derivatives of $\mathrm{FB}_{1}$ were monitored at excitation/emission of $300 / 440 \mathrm{~nm}$. The limit of quantitation was $20 \mathrm{pg}$ per injection. The measured urinary $\mathrm{FB}_{1}$ levels were adjusted by creatinine concentration of corresponding urine samples to obtain the exposure parameters in units of $\mathrm{pg} / \mathrm{mg}$ creatinine.

\section{Statistical analysis}

Descriptive statistics, including mean $\pm \mathrm{SD}$, median, and range (or distribution quadrants), were calculated for each exposure parameter. Detailed epidemiological questionnaire data, including tobacco, alcohol consumption, dietary pattern, etc., were assessed as well. The association between exposure parameters with the risk of ESCC was estimated by conditional logistic regression model. Odds ratios (ORs) and their 95\% confidence interval (CI) for ESCC risk were calculated. The interaction of mycotoxins was estimated by using crossover analysis. Interaction parameters, including relative excess risk due to interaction, proportion attributable to interaction, and synergy index, were calculated using methods described by Andersson et al. [43]. All statistical tests were two-sided, with $p$-value of $<0.05$ considered statistically significant. All analyses were conducted in SAS 9.4 (SAS Institute, Cary, NC, USA).

\section{Results \\ Population characteristics}

Demographic information is summarized in Table 1. There were no significant differences between cases and controls in cumulative alcohol and tobacco uses. Significant differences were found between cases and controls in education attainment, as well as individual income per month at the time of recruitment and 10 years before the recruitment. 
Table 1 Demographic and socioeconomic characteristics of cases and matched controls

\begin{tabular}{|c|c|c|c|c|}
\hline Characteristic & $\begin{array}{l}\text { Cases }(n=190) \\
\text { No. }(\%)^{c}\end{array}$ & Controls $(n=380)$ & $p^{a}$ & OR $(95 \% \mathrm{Cl})^{\mathrm{b}}$ \\
\hline \multicolumn{5}{|l|}{ Gender } \\
\hline Male & $111(58.4)$ & $222(58.4)$ & 1.00 & 1.0 \\
\hline Female & $79(41.6)$ & $158(41.6)$ & & $1.00(0.70-1.43)$ \\
\hline \multicolumn{5}{|l|}{ Educational attainment } \\
\hline Illiterate & $113(59.5)$ & $185(48.8)$ & $<0.001$ & 1.00 \\
\hline Primary school & $55(29.0)$ & $106(28.0)$ & & $0.74(0.47-1.15)$ \\
\hline Middle school & $17(9.0)$ & $64(16.9)$ & & $0.30(0.15-0.60)$ \\
\hline High school and above & $5(2.6)$ & $24(6.3)$ & & $0.25(0.09-0.72)$ \\
\hline $\mathrm{P}$ for trend & & & & $<0.001$ \\
\hline \multicolumn{5}{|l|}{ Marital Status } \\
\hline Married & $146(76.8)$ & $314(82.9)$ & 0.07 & 1.0 \\
\hline Not Married (divorced, widowed, single) & $44(23.2)$ & $65(17.2)$ & & $1.54(0.96-2.47)$ \\
\hline \multicolumn{5}{|l|}{ Ten-years-ago income, yuan/month } \\
\hline$<50$ & $52(27.4)$ & $108(28.4)$ & 0.01 & 1.0 \\
\hline $50-100$ & $43(22.6)$ & $127(33.4)$ & & $0.73(0.46-1.18)$ \\
\hline$\geq 100$ & $95(50.0)$ & $145(38.2)$ & & $1.44(0.92-2.26)$ \\
\hline$P$ for trend & & & & 0.07 \\
\hline \multicolumn{5}{|l|}{ Current income, yuan/month } \\
\hline$<100$ & $56(29.5)$ & $75(19.7)$ & 0.02 & 1.0 \\
\hline $100-300$ & $82(43.2)$ & $175(46.1)$ & & $0.63(0.41-0.97)$ \\
\hline$\geq 300$ & $52(27.4)$ & $130(34.2)$ & & $0.50(0.30-0.83)$ \\
\hline$P$ for trend & & & & 0.008 \\
\hline \multicolumn{5}{|l|}{ Mean \pm SD } \\
\hline Age, years & $62.0 \pm 7.9$ & $61.9 \pm 7.8$ & 0.85 & $1.00(0.98-1.03)$ \\
\hline Cumulative alcohol intake (kg-year) & $2.6 \pm 2.4$ & $2.9 \pm 3.3$ & 0.36 & $0.96(0.87-1.05)$ \\
\hline Cumulative tobacco use (pack-year) & $39.6 \pm 47.4$ & $47.0 \pm 66.5$ & 0.25 & $1.00(0.99-1.00)$ \\
\hline
\end{tabular}

${ }^{a}$ weighted $t$ test of mean difference between cases and controls or conditional logistic regression of difference between cases and controls, as appropriate bodds ratio (OR) and $95 \%$ confidence interval (Cl) were calculated using conditional logistic regression or unconditional logistic regression with adjustment of age and gender, as appropriate

cpercentage may not add to 100 because of rounding

\section{Mycotoxins exposure and ESCC risks}

Urinary free $\mathrm{FB}_{1}$ was detectable in $95.8 \%(181 / 189)$ of the ESCC cases and $84.2 \%(319 / 379)$ of the controls, and serum $\mathrm{AFB}_{1}$-lysine was detectable in $90.7 \%$ $(146 / 161)$ of the cases and $69.3 \%(142 / 205)$ of the controls. The mean, median, standard deviation, and quartiles for $\mathrm{AFB}_{1}$-lysine as well as urinary $\mathrm{FB}_{1}$ for both cases and controls are summarized in Table 2 and Fig. 2. Both urinary free $\mathrm{FB}_{1}$ (Fig. 2a) and serum $\mathrm{AFB}_{1}$-lysine (Fig. $2 \mathrm{~b}$ ) levels were significantly higher in cases than in controls $(p<0.01$ and $<0.05$, respectively).

Table 3 shows the ESCC risks associated with exposure to $\mathrm{FB}_{1}$ and $\mathrm{AFB}_{1}$. Continuous variables were converted into binary categorical variables based on the population median for urinary $\mathrm{FB}_{1}$ and serum $\mathrm{AFB}_{1}$ in
Table 2 Serum $A F B_{1}$-lysine and Urinary $F_{1}$ levels of Huaian Esophageal Cancer Case and Control samples

\begin{tabular}{llll}
\hline & & $\begin{array}{l}\mathrm{AFB}_{1} \text {-lysine } \\
(\mathrm{pg} / \mathrm{mg} \text { albumin })\end{array}$ & $\begin{array}{l}\text { Urinary FB } \\
(\mathrm{pg} / \mathrm{mg} \text { creatinine })\end{array}$ \\
\hline Case & Median & 1.77 & 176.13 \\
& mean \pm SD & $6.03 \pm 13.36$ & $470.41 \pm 1215.95$ \\
& Quartile $(25 \& 75 \%)$ & $(1.04,4.7)$ & $(70.77,388.67)$ \\
Control & Median & 1.49 & 56.92 \\
& mean \pm SD & $3.67 \pm 11.12$ & $213.56 \pm 437.75$ \\
& Quartile (25 \& 75\%) & $(0.67,2.35)$ & $(19.78,202.27)$ \\
$P$ value & & $<0.05$ & $<0.01$ \\
\hline
\end{tabular}



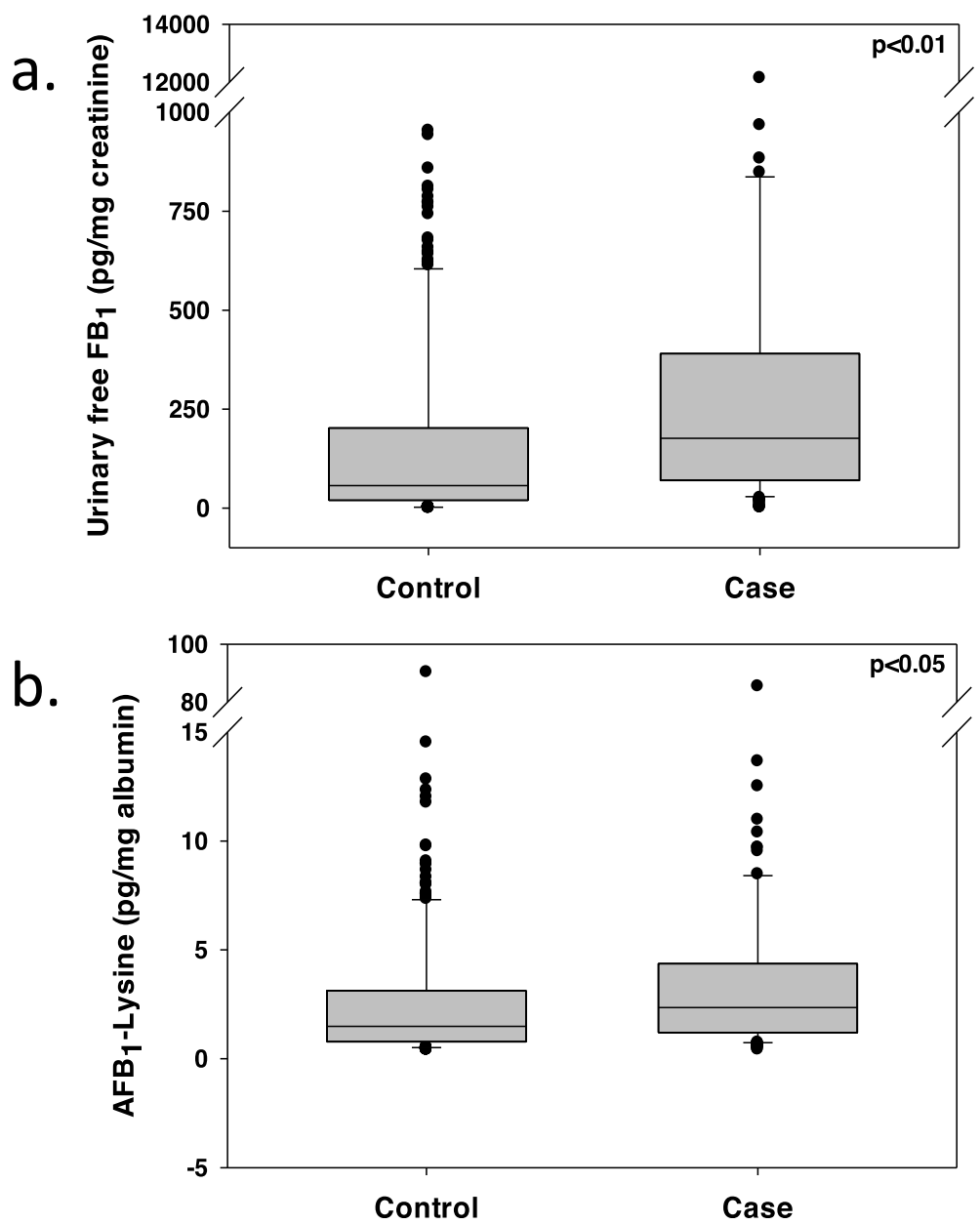

Fig. 2 Comparison of biomarker levels between cases and controls. Plots depict overall levels of a urinary $F_{1}$ and $\mathbf{b}$ serum $A F B_{1}$-lysine adducts in esophageal cancer case and control samples. Boxes in the plot represent 25 and 75 percentiles, with the medians as the middle lines. Bars represent 5 and 95 percentiles of data

control groups, thereby dividing the populations into low- and high- exposure groups. For both urinary $\mathrm{FB}_{1}$ and $\mathrm{AFB}_{1}$, high exposure groups have significantly higher odds ratios for $\operatorname{ESCC}(p<0.001$ for all), with greater percentage of cases categorized as high exposure for both $\mathrm{FB}_{1}$ and $\mathrm{AFB}_{1}$ (Table 4).

\section{Interaction between two mycotoxins exposures}

Evaluation of interaction between $\mathrm{FB}_{1}$ and $\mathrm{AFB}_{1}$ exposure on ESCC risks is summarized in Table 4. The risk for high levels of exposure to both $\mathrm{FB}_{1}$ and $\mathrm{AFB}_{1}$ is significantly higher than that of either high $\mathrm{FB}_{1}$ or high $\mathrm{AFB}_{1}$ alone. The combination of high

Table 3 ESCC risk and urinary free $\mathrm{FB}_{1}$ and serum $\mathrm{AFB}_{1}$-lysine levels

\begin{tabular}{|c|c|c|c|c|c|}
\hline & Range $^{a}$ & Cases (\%) & Controls (\%) & OR $(95 \% \mathrm{Cl})$ & $P$ \\
\hline \multicolumn{6}{|c|}{ Urinary $\mathrm{FB}_{1}$ (pg/mg creatinine) } \\
\hline Low & $<56.92$ & $40(21.05)$ & $190(50.0)$ & 1 & \\
\hline High & $\geq 56.92$ & $150(78.95)$ & $190(50.0)$ & $3.689(2.438-5.582)$ & $<0.001$ \\
\hline \multicolumn{6}{|c|}{$\mathrm{AFB}_{1}$-Lysine (pg/mg albumine) } \\
\hline Low & $<1.49$ & $64(33.68)$ & $194(51.05)$ & 1 & \\
\hline High & $\geq 1.49$ & $126(66.32)$ & $186(48.95)$ & $2.629(1.711-4.041)$ & $<0.001$ \\
\hline
\end{tabular}

Range of low and high levels for urinary $\mathrm{FB}_{1}$ and serum $\mathrm{AFB}_{1}$-lysine are determined by median level of control samples 
Table 4 Interaction of $\mathrm{FB}_{1}$ and $\mathrm{AFB}_{1}$ exposure on risk of esophageal cancer

\begin{tabular}{|c|c|c|c|c|c|}
\hline $\mathrm{FB}_{1}$ exposure $^{a}$ & $\mathrm{AFB}_{1}$ exposure $^{\mathrm{b}}$ & Cases (\%) & Controls (\%) & $\mathrm{p}$ & OR $(95 \% \mathrm{Cl})$ \\
\hline Low & Low & $14(7.36)$ & $100(26.32)$ & & 1 \\
\hline High & Low & $50(26.32)$ & $88(23.16)$ & $<0.001$ & $4.057(2.101,7.834)$ \\
\hline Low & High & $25(13.16)$ & $90(23.68)$ & 0.060 & $1.983(0.972,4.048)$ \\
\hline High & High & $101(53.16)$ & $102(26.84)$ & $<0.001$ & $7.070(3.791,13.187)$ \\
\hline \multicolumn{5}{|c|}{ Relative excess risk due to interaction (RERI) } & $2.030(-0.591,4.651)$ \\
\hline \multicolumn{5}{|c|}{ Proportion attributable to interaction (AP) } & $0.287(-0.029,0.603)$ \\
\hline \multicolumn{5}{|c|}{ Synergy index (S) } & $1.502(0.864,2.612)$ \\
\hline
\end{tabular}

Exposure levels are indicated by levels of urinary $\mathrm{FB}_{1}{ }^{\mathrm{a}}$ and serum $\mathrm{AFB}_{1}$-lysine ${ }^{\mathrm{b}}$

exposure to both $\mathrm{FB}_{1}$ and $\mathrm{AFB}_{1}$ resulted in positive interaction, indicating a potentially greater-thanadditive risk with co-exposure of $\mathrm{FB}_{1}$ and $\mathrm{AFB}_{1}$ in affecting ESCC risks.

\section{Discussion}

In the present study, we assessed the exposure to potent mycotoxins, $\mathrm{AFB}_{1}$ and $\mathrm{FB}_{1}$, using corresponding exposure biomarkers and evaluated their associations with the risk for ESCC in Huaian area, China. We evaluated risk associated with individual factors, as well as binary interaction between factors based on logistic regression. Based on the results, high level exposure to $\mathrm{AFB}_{1}$ and $\mathrm{FB}_{1}$ were associated with increased risk to $\mathrm{ESCC}$, and greater-than-additive interaction exists between high $\mathrm{AFB}_{1}$ and $\mathrm{FB}_{1}$ exposure. The overall dietary patterns and staple food have not been changed for decades in the study area and populations $[5,19,40]$, despite of possible periodic variations; therefore, measurement for biomarker levels are reflective of both the current and past exposures, which might be even higher than the currently measured exposure levels.

Previous studies have confirmed the association between FN exposure and ESCC risks, with the earliest association between ESCC and FN was established in the Transkei region of southern Africa, an international esophageal cancer hot spot [7, 44]. Studies have found significantly higher levels of Fusarium verticillioides infection and $\mathrm{FB}_{1}$ and $\mathrm{B}_{2}$ levels in homegrown corn samples collected from higher-risk areas compared to those from lower-risk areas [45-48]. Various populations within the region were also found to have exposure levels exceeding the recommended provisional maximum tolerable daily intake of $2 \mu \mathrm{g} / \mathrm{kg}$ bw [46, 47, 49]. In China, a survey of 282 corn samples from 6 provinces found detectable $\mathrm{FB}_{1}$ in $99.6 \%$ samples, with $25.2 \%$ of samples having levels higher than $5 \mathrm{mg} / \mathrm{kg}$ [50]. In high risk counties of Cixian and Linxian (now Linzhou), $\mathrm{FB}_{1}$ has been detected in all corn samples collected from local households, where half of the samples, with heavy mold contamination, have a mean $\mathrm{FB}_{1}$ level of $74 \mathrm{mg} / \mathrm{kg}$ (range: $18-155 \mathrm{mg} / \mathrm{kg}$ ), while the other half, without visible mold contamination, showed an average $\mathrm{FB}_{1}$ level of $35.3 \mathrm{mg} / \mathrm{kg}$ (range: $20-60 \mathrm{mg} / \mathrm{kg}$ ) [8]. However, a biomarkers-based study found no association of sphingosine, sphinganine, and sphinganine/sphingosine ratios with ESCC [51], though later studies suggested that sphingolipid levels may not be sensitive biomarkers for exposure in human populations [48, 49]. Although these studies suggested the potential role of $\mathrm{FB}_{1}$ exposure in esophageal cancer development, confirmations of $\mathrm{FB}_{1}$ exposure in human disease risks with validated exposure biomarkers have not been studied and published.

While AFs are more commonly associated with risk for hepatocellular carcinoma (HCC) [9], evidences have suggested their potential link to the risk of ESCC. Cocontamination of AFs with FNs has been reported in high-risk areas of ESCC in China, including Cixian and Linxian (now Linzhou), as well as Huaian regions [8, 19]. The association between AFs contamination and risks of esophageal cancer was further demonstrated by a study in Golestan province of Iran, where the total AFs levels in wheat flour samples was significantly higher in high-risk areas compared to low-risk areas [52]. The current study, which detected exposure to $\mathrm{AFB}_{1}$ via serum exposure biomarkers, confirms the cocontamination of $\mathrm{AFB}_{1}$ with $\mathrm{FB}_{1}$ in the high-risk area, as well as the association of high $\mathrm{AFB}_{1}$ exposure with ESCC risk. Furthermore, the current study found a greaterthan-additive interaction between $\mathrm{AFB}_{1}$ and $\mathrm{FB}_{1}$ exposure via both binary interaction assay and higher-order analysis. It should be noted, however, that our study found marginal significance $(p=0.06)$ in terms of association of ESCC with low $\mathrm{FB}_{1}$-high $\mathrm{AFB}_{1}$ exposures. This may be due to the lack of sufficient participant numbers recruited in our study $(\mathrm{n})$ to delineate the higher significance. On the other hand, the role of $\mathrm{AFB}_{1}$ exposure in contributing risks of cancers other than liver, such as lung, colorectal and esophagus, have been rarely examined $[53,54]$. While the association between food $\mathrm{AFB}_{1}$ contamination and ESCC has been reported, there is a very high likelihood that co-contaminations of $\mathrm{AFB}_{1}$ with $\mathrm{FB}_{1}$ or other mycotoxins is also present in the study areas $[33,52]$. While the potential mechanisms of $\mathrm{AFB}_{1}$ 
in ESCC risk remain to be elucidated, in an in vitro study, $\mathrm{AFG}_{1}$, a less toxic variant of $\mathrm{AFs}$, is shown to reduce the expression of HLA-I, TAP-1, and LMP-2, critical components in antigen presentation and antigen processing, in adult esophageal epithelial cells, which can ultimately lead to defect in antigen presentation to T-lymphocytes, potentiating tumorigenesis via escaped immune surveillance, therefore potentially linking AF exposure to esophageal cancer [55].

Studies have demonstrated that the co-contamination of AFs and FNs, and the potential interaction of the two, may play a great role in etiology of many mycotoxinrelated diseases and health outcomes. Epidemiological studies have pin-pointed the potential contributory effect of $\mathrm{FB}_{1}$ on $\mathrm{HCC}$ linked to $\mathrm{AFB}_{1}$ exposure, with cocontamination of $\mathrm{AFB}_{1}$ and $\mathrm{FB}_{1}$ detected in several areas with historically high risks for $\mathrm{HCC}$, including parts of Guatemala and China [19, 20, 34, 35]. Using molecular biomarkers of exposure, Shirima et al. found chronical co-exposure to both AF and FN among young Tanzanian children via contaminated diet, and the levels were negatively associated with growth parameters, implying contribution to growth impairments [56, 57]. At the same time, in animal and model organism studies, combinations of the two mycotoxins often showed greater toxic effects when compared to either $\mathrm{AFB}_{1}$ or $\mathrm{FB}_{1}$ alone, with some studies pointing to a clear additive effect on toxicity, and others showing potentially synergistic effects on tumorigenesis; for example, $\mathrm{FB}_{1}$ was shown to promote $\mathrm{AFB}_{1}$-initiated liver tumor in rainbow trout and development of pre-neoplastic liver lesions in F344 rats [36-38]. The mechanisms of toxicity suggest that, while $\mathrm{FB}_{1}$ does not act as direct carcinogen like $\mathrm{AFB}_{1}$, it can be a potent promoter of $\mathrm{AFB}_{1}$-induced tumorigenesis, as $\mathrm{FB}_{1}$ can significantly alter sphingolipid profile in both animals and humans by inhibiting ceramide synthase, which can further affect apoptosis and potentially other signaling pathways [37, 38, 58-61]. Although further studies are required to fully elucidate the interaction between $\mathrm{AFB}_{1}$ and $\mathrm{FB}_{1}$ in human and animal carcinogenesis and other adverse health effects, it is clear that analysis of single mycotoxin may not be sufficient in assessment of potential cancer risks, and the setting of regulatory standards, which were established based on individual toxicant or carcinogen, may not necessarily be protective enough when considering the combinative effect of mycotoxins.

As shown in Table 1, we did not find significant association of ESCC cases with alcohol consumption and smoking status in the current study, which is consistent with many previously published studies in China, including studies for liver cancer, as well as studies conducted in the same area for esophageal cancer [5, 40, 62, 63]. The major reasons for lack of such association are the prevalence of alcohol drinking (nearly $100 \%$ in the study participants) and the nature of the matched case-control design. The same would apply for the lack of association for smoking status, with almost $100 \%$ study participants are active (males) or secondhand (females) smokers. The limitation of this study includes the nature of casecontrol study design, which can't reveal a causative correlation, but only show associations.

\section{Conclusions}

Mycotoxin exposure, especially to $\mathrm{AFB}_{1}$ and $\mathrm{FB}_{1}$, was associated with the risk of ESCC, and a greater-thanadditive interaction between co-exposures to these two mycotoxins may contribute to the increased risk of ESCC in the studied population in Huaian area, China.

\section{Abbreviations \\ $A F B_{1}$ : Aflatoxin $B_{1}$; EAC: Adenocarcinoma; ESCC: Esophageal squamous cell carcinoma; $\mathrm{FB}_{1}$ : Fumonisin $\mathrm{B}_{1}$; HCC: Hepatocellular carcinoma}

\section{Acknowledgements}

Field study team members from Huaian Center for Disease Control and Prevention and voluntary study participants who provided their blood and urine samples are greatly appreciated.

\section{Authors' contributions}

KX participated in biomarkers analyses and the writing of manuscript. LT participated in study design, performed biomarkers measurements, as well as statistical analyses. GS, SW, and XH participated in study design, and participated in collection of field samples and questionnaires, as well as coordination of the field studies. JSW participated in study design and act as the principal investigator for the entire project, whom supervises various stages of the study. All authors read and approved the final manuscript.

\section{Funding}

This study was supported by grants CA94683 (for field study including in the design of the study and data collection) and CA90997 (for laboratory analysis including biomarker analysis and interpretation of data) from National Cancer Institute/National Institutes of Health to Dr. Jia-Sheng Wang. The manuscript writing and publication cost are supported by the University of Georgia.

\section{Availability of data and materials}

The datasets used and/or analyzed during the current study are available from the request to the corresponding author.

\section{Ethics approval and consent to participate}

The study protocols including ethics guidelines and bilingual consent forms (English and Chinese) were approved by the Institutional Review Boards for human subjects at Southeast University School of Public Health and Texas Tech University (human subject assurance number: 00001568) and was compliant with human research ethics guidelines of the respective institutions. Written consents were obtained from all participants in the study.

\section{Consent for publication}

Not applicable.

\section{Competing interests}

The authors declare that they have no competing interests.

\section{Author details}

'Department of Environmental Health Science, College of Public Health, University of Georgia, 150 Green Street, Athens, GA 30602, USA. ${ }^{2}$ Southeast University School of Public Health, Nanjing, Jiangsu, China. ${ }^{3}$ Huaian District Center for Disease Control and Prevention, Huaian, Jiangsu, China. 


\section{Received: 10 September 2019 Accepted: 5 December 2019} Published online: 16 December 2019

\section{References}

1. American Cancer Society. Global Cancer Facts \& Figures. 3rd ed. Atlanta: American Cancer Society; 2015

2. Jemal A, Bray F, Center MM, Ferlay J, Ward E, Forman D. Global cancer statistics. CA Cancer J Clin. 2011;61(2):69-90.

3. Torre LA, Bray F, Siegel RL, Ferlay J, Lortet-Tieulent J, Jemal A. Global cancer statistics, 2012. CA Cancer J Clin. 2015;65(2):87-108.

4. Kamangar F, Malekzadeh R, Dawsey SM, Saidi F. Esophageal cancer in northeastern Iran: a review. Arch Iran Med. 2007;10(1):70-82.

5. Wang Z, Tang L, Sun G, Tang Y, Xie Y, Wang S, et al. Etiological study of esophageal squamous cell carcinoma in an endemic region: a populationbased case control study in Huaian, China. BMC Cancer. 2006;6:287.

6. Zhang Y. Epidemiology of esophageal cancer. World J Gastroenterol. 2013; 19(34):5598-606.

7. Marasas WF. Discovery and occurrence of the fumonisins: a historical perspective. Environ Health Perspect. 2001;109(Suppl 2):239-43.

8. Chu FS, Li GY. Simultaneous occurrence of fumonisin B1 and other mycotoxins in moldy corn collected from the People's Republic of China in regions with high incidences of esophageal cancer. Appl Environ Microbiol. 1994;60(3):847-52.

9. IARC. In: Wild CP, Miller JD, Groopman JD, editors. Mycotoxin control in lowand middle- income countries. Lyon: WHO; 2015.

10. IARC. Some Traditional Herbal Medicines, Some Mycotoxins, Naphthalene and Styrene. In: IARC Monographs on the Evaluation of Carcinogenic Risks to Humans, vol. 82. Lyon: IARC Press; 2002. p. 171-300.

11. Kensler TW, Roebuck BD, Wogan GN, Groopman JD. Aflatoxin: a 50-year odyssey of mechanistic and translational toxicology. Toxicol Sci. 2011; 120(Suppl 1):S28-48.

12. Marasas WF. Fumonisins: history, world-wide occurrence and impact. Adv Exp Med Biol. 1996;392:1-17.

13. Shephard GS, Thiel PG, Stockenstrom S, Sydenham EW. Worldwide survey of fumonisin contamination of corn and corn-based products. J AOAC Int. 1996;79(3):671-87.

14. Etcheverry M, Nesci A, Barros G, Torres A, Chulze S. Occurrence of Aspergillus section Flavi and aflatoxin B1 in corn genotypes and corn meal in Argentina. Mycopathologia. 1999;147(1):37-41.

15. Abbas HK, Cartwright RD, Xie W, Thomas SW. Aflatoxin and fumonisin contamination of corn (maize, Zea mays) hybrids in Arkansas. Crop Prot. 2006;25(1):1-9.

16. Kumi J, Mitchell NJ, Asare GA, Dotse E, Kwaa F, Phillips TD, et al. Aflatoxins and fumonisins contamination of home-made food (weanimix) from cereallegume blends for children. Ghana Med J. 2014;48(3):121-6.

17. Madbouly AK, Ibrahim MI, Sehab AF, Abdel-Wahhab MA. Co-occurrence of mycoflora, aflatoxins and fumonisins in maize and rice seeds from markets of different districts in Cairo, Egypt. Food Addit Contam Part B Surveill. 2012;5(2):112-20.

18. Rocha LO, Nakai VK, Braghini R, Reis TA, Kobashigawa E, Correa B. Mycoflora and co-occurrence of fumonisins and aflatoxins in freshly harvested corn in different regions of Brazil. Int J Mol Sci. 2009;10(11):5090-103.

19. Sun G, Wang S, Hu X, Su J, Zhang Y, Xie Y, et al. Co-contamination of aflatoxin B-1 and fumonisin B-1 in food and human dietary exposure in three areas of China. Food Addit Contam A. 2011;28(4):461-70.

20. Torres O, Matute J, Waes JG-V, Maddox JR, Gregory SG, Ashley-Koch AE, et al. Human health implications from co-exposure to aflatoxins and fumonisins in maize-based foods in Latin America: Guatemala as a case study. World Mycotoxin J. 2015;8(2):143-59.

21. Yoshizawa T, Yamashita A, Chokethaworn N. Occurrence of fumonisins and aflatoxins in corn from Thailand. Food Addit Contam. 1996:13(2):163-8.

22. Wild CP, Gong YY. Mycotoxins and human disease: a largely ignored global health issue. Carcinogenesis. 2010;31(1):71-82

23. Dutton MF. Fumonisins, mycotoxins of increasing importance: their nature and their effects. Pharmacol Ther. 1996;70(2):137-61.

24. Sun G, Wang S, Hu X, Su J, Huang T, Yu J, et al. Fumonisin B1 contamination of home-grown corn in high-risk areas for esophageal and liver cancer in China. Food Addit Contam. 2007;24(2):181-5.

25. Perera FP, Weinstein IB. Molecular epidemiology: recent advances and future directions. Carcinogenesis. 2000;21(3):517-24.
26. Sabbioni G, Ambs S, Wogan GN, Groopman JD. The aflatoxin-lysine adduct quantified by high-performance liquid chromatography from human serum albumin samples. Carcinogenesis. 1990;11(11):2063-6.

27. Cai Q, Tang L, Wang JS. Validation of fumonisin biomarkers in F344 rats. Toxicol Appl Pharmacol. 2007;225(1):28-39.

28. Riley RT, Torres O, Showker JL, Zitomer NC, Matute J, Voss KA, et al. The kinetics of urinary fumonisin B1 excretion in humans consuming maizebased diets. Mol Nutr Food Res. 2012;56(9):1445-55.

29. Shephard GS, Van Der Westhuizen L, Sewram V. Biomarkers of exposure to fumonisin mycotoxins: a review. Food Addit Contam. 2007;24(10):1196-201.

30. Torres O, Matute J, Gelineau-van Waes J, Maddox JR, Gregory SG, AshleyKoch $A E$, et al. Urinary fumonisin B1 and estimated fumonisin intake in women from high- and low-exposure communities in Guatemala. Mol Nutr Food Res. 2014;58(5):973-83.

31. WHO. Fumonisin B1. Environmental Health Criteria 219. Geneva: World Health Organization; 2000. p. 1-134

32. Sydenham EW, Thiel PG, Marasas WFO, Shephard GS, Van Schalkwyk DJ, Koch KR. Natural occurrence of some Fusarium mycotoxins in corn from low and high esophageal cancer prevalence areas of the Transkei, southern Africa. J Agric Food Chem. 1990;38(10):1900-3.

33. Alizadeh AM, Roshandel G, Roudbarmohammadi S, Roudbary M, Sohanaki $H$, Ghiasian SA, et al. Fumonisin B1 contamination of cereals and risk of esophageal cancer in a high risk area in northeastern Iran. Asian Pac J Cancer Prev. 2012;13(6):2625-8.

34. Ueno $Y$, lijima $K$, Wang S-D, Sugiura $Y$, Sekijima $M$, Tanaka $T$, et al. Fumonisins as a possible contributory risk factor for primary liver cancer: a 3-year study of corn harvested in Haimen, China, by HPLC and ELISA. Food Chem Toxicol. 1997:35(12):1143-50.

35. Li F-Q, Yoshizawa T, Kawamura O, Luo X-Y, Li Y-W. Aflatoxins and fumonisins in corn from the high-incidence area for human hepatocellular carcinoma in Guangxi, China. J Agric Food Chem. 2001;49(8):4122-6.

36. Qian G, Tang L, Lin S, Xue KS, Mitchell NJ, Su J, et al. Sequential dietary exposure to aflatoxin B1 and fumonisin B1 in F344 rats increases liver preneoplastic changes indicative of a synergistic interaction. Food Chem Toxicol. 2016:95:188-95.

37. Carlson DB, Williams DE, Spitsbergen JM, Ross PF, Bacon CW, Meredith FI, et al. Fumonisin B1 promotes aflatoxin B1 and N-methyl-N'-nitronitrosoguanidine-initiated liver tumors in rainbow trout. Toxicol Appl Pharmacol. 2001;172(1):29-36.

38. Gelderblom WC, Marasas WF, Lebepe-Mazur S, Swanevelder S, Vessey CJ, Hall PL. Interaction of fumonisin B(1) and aflatoxin B(1) in a short-term carcinogenesis model in rat liver. Toxicology. 2002;171(2-3):161-73.

39. Sabbioni G, Skipper PL, Buchi G, Tannenbaum SR. Isolation and characterization of the major serum albumin adduct formed by aflatoxin B1 in vivo in rats. Carcinogenesis. 1987;8(6):819-24.

40. Huang GL, Yang L, Su M, Wang SK, Yin H, Wang JS, et al. Vitamin D3 and beta-carotene deficiency is associated with risk of esophageal squamous cell carcinoma - results of a case-control study in China. Asian Pac J Cancer Prev. 2014;15(2):819-23.

41. Qian G, Tang L, Wang F, Guo X, Massey ME, Williams JH, et al. Physiologically based toxicokinetics of serum aflatoxin B1-lysine adduct in F344 rats. Toxicology. 2013;303:147-51.

42. Xu L, Cai Q, Tang L, Wang S, Hu X, Su J, et al. Evaluation of fumonisin biomarkers in a cross-sectional study with two high-risk populations in China. Food Addit Contam Part A Chem Anal Control Expo Risk Assess. 2010;27(8):1161-9.

43. Andersson T, Alfredsson L, Kallberg H, Zdravkovic S, Ahlbom A. Calculating measures of biological interaction. Eur J Epidemiol. 2005;20(7):575-9.

44. Jaskiewicz K, Marasas WF, van der Walt FE. Oesophageal and other main cancer patterns in four districts of Transkei, 1981-1984. S Afr Med J. 1987;72(1):27-30.

45. Rheeder J, Marasas W, Thiel P, Sydenham E, Shephard G, Van Schalkwyk D. Fusarium moniliforme and fumonisins in corn in relation to human esophageal cancer in Transkei. Phytopathology. 1992;82(3):353-7.

46. Shephard GS, Marasas WF, Burger HM, Somdyala NI, Rheeder JP, Van der Westhuizen $L$, et al. Exposure assessment for fumonisins in the former Transkei region of South Africa. Food Addit Contam. 2007;24(6):621-9.

47. Shephard GS, van der Westhuizen L, Gatyeni PM, Somdyala NI, Burger HM, Marasas WF. Fumonisin mycotoxins in traditional Xhosa maize beer in South Africa. J Agric Food Chem. 2005:53(24):9634-7.

48. van der Westhuizen L, Shephard GS, Rheeder JP, Burger HM. Individual fumonisin exposure and sphingoid base levels in rural populations consuming maize in South Africa. Food Chem Toxicol. 2010;48(6):1698-703. 
49. van der Westhuizen L, Shephard GS, Rheeder JP, Somdyala NI, Marasas WF. Sphingoid base levels in humans consuming fumonisin-contaminated maize in rural areas of the former Transkei, South Africa: a cross-sectional study. Food Addit Contam Part A Chem Anal Control Expo Risk Assess. 2008;25(11):1385-91.

50. Gong HZ, Ji R, Li YX, Zhang HY, Li B, Zhao Y, et al. Occurrence of fumonisin $B(1)$ in corn from the main corn-producing areas of China. Mycopathologia. 2009;167(1):31-6.

51. Abnet CC, Borkowf CB, Qiao YL, Albert PS, Wang E, Merrill AH Jr, et al. Sphingolipids as biomarkers of fumonisin exposure and risk of esophageal squamous cell carcinoma in China. Cancer Causes Control. 2001;12(9):821-8.

52. Ghasemi-Kebria F, Joshaghani H, Taheri NS, Semnani S, Aarabi M, Salamat F, et al. Aflatoxin contamination of wheat flour and the risk of esophageal cancer in a high risk area in Iran. Cancer Epidemiol. 2013;37(3):290-3.

53. Vleet TRV, Klein PJ, Jr RAC. Metabolism and cytotoxicity of aflatoxin B 1 in cytochrome P-450-expressing human lung cells. J Toxic Environ Health A. 2002;65(12):853-67.

54. Carvajal-Moreno M. Do gastroenterologists consider aflatoxins as origin of digestive system cancers. J Pharmacovigil. 2017;5:242.

55. Li Z, Cui J, Zhang X, Kang W. Aflatoxin G 1 reduces the molecular expression of HLA-I, TAP-1 and LMP-2 of adult esophageal epithelial cells in vitro. Toxicol Lett. 2010;195(2):169-73.

56. Shirima CP, Kimanya ME, Kinabo JL, Routledge MN, Srey C, Wild CP, et al. Dietary exposure to aflatoxin and fumonisin among Tanzanian children as determined using biomarkers of exposure. Mol Nutr Food Res. 2013:57(10):1874-81.

57. Shirima CP, Kimanya ME, Routledge MN, Srey C, Kinabo JL, Humpf HU, et al. A prospective study of growth and biomarkers of exposure to aflatoxin and fumonisin during early childhood in Tanzania. Environ Health Perspect. 2015;123(2):173-8.

58. Clarke R, Connolly L, Frizzell C, Elliott CT. Cytotoxic assessment of the regulated, co-existing mycotoxins aflatoxin $\mathrm{B} 1$, fumonisin $\mathrm{B} 1$ and ochratoxin, in single, binary and tertiary mixtures. Toxicon. 2014;90:70-81.

59. Mckean C, Tang L, Tang M, Billam M, Wang Z, Theodorakis CW, et al. Comparative acute and combinative toxicity of aflatoxin B1 and fumonisin B1 in animals and human cells. Food Chem Toxicol. 2006;44(6):868-76.

60. Riley RT, Torres O, Matute J, Gregory SG, Ashley-Koch AE, Showker JL, et al. Evidence for fumonisin inhibition of ceramide synthase in humans consuming maize-based foods and living in high exposure communities in Guatemala. Mol Nutr Food Res. 2015;59(11):2209-24.

61. Tessari EN, Oliveira CA, Cardoso AL, Ledoux DR, Rottinghaus GE. Effects of aflatoxin $\mathrm{B} 1$ and fumonisin $\mathrm{B} 1$ on body weight, antibody titres and histology of broiler chicks. Br Poult Sci. 2006;47(3):357-64.

62. Xu L, Qian G, Tang L, Su J, Wang JS. Genetic variations of hepatitis B virus and serum aflatoxin-lysine adduct on high risk of hepatocellular carcinoma in southern Guangxi, China. J Hepatol. 2010;53(4):671-6.

63. Wang JS, Huang T, Su J, Liang F, Wei Z, Liang Y, et al. Hepatocellular carcinoma and aflatoxin exposure in Zhuqing Village, Fusui County, People's Republic of China. Cancer Epidemiol Biomarkers Prev. 2001;10(2):143-6.

\section{Publisher's Note}

Springer Nature remains neutral with regard to jurisdictional claims in published maps and institutional affiliations.

\section{Ready to submit your research? Choose BMC and benefit from}

- fast, convenient online submission

- thorough peer review by experienced researchers in your field

- rapid publication on acceptance

- support for research data, including large and complex data types

- gold Open Access which fosters wider collaboration and increased citations

- maximum visibility for your research: over $100 \mathrm{M}$ website views per year

At $\mathrm{BMC}$, research is always in progress.

Learn more biomedcentral.com/submissions 